\title{
Analyzing Acute Care Surgery Patient Flow in the Emergency Department During COVID-19 Pandemic
}

\author{
Georgios FERETZAKIS ${ }^{\mathrm{a}, \mathrm{b}, \mathrm{c}, 1}$, Georgios KARLIS ${ }^{\mathrm{d}}$, Konstantinos TSEKOURAS ${ }^{\mathrm{d}}$, \\ Stamatios ORFANOS ${ }^{\mathrm{d}}$, Evangelos LOUPELIS ${ }^{\mathrm{b}}$, Stavroula PETROPOULOU ${ }^{\mathrm{b}}$, \\ Konstantinos MANTZOURANIS ${ }^{\mathrm{e}}$, Makrina TSAFARIDOU ${ }^{\mathrm{b}}$, \\ Rea CHATZIKYRIAKOU ${ }^{f}$, Aikaterini SOFIANOU ${ }^{d}$, Paraskevi ZAFEIRIADOU ${ }^{d}$, \\ Aikaterini TIKA $^{\mathrm{g}}$, Ilias DALAINAS ${ }^{\mathrm{g}}$ and Vasileios KALDIS ${ }^{\mathrm{d}}$ \\ a School of Science and Technology, Hellenic Open University, Patras, Greece \\ b Sismanogleio General Hospital, IT department, Marousi, Greece \\ c Sismanogleio General Hospital, Department of Quality Control, Research and \\ Continuing Education, Marousi, Greece \\ d Sismanogleio General Hospital, Emergency Department, Marousi, Greece \\ e Sismanogleio General Hospital, 1st Pulmonology Department, Marousi, Greece \\ f Sismanogleio General Hospital, Hematology Laboratory, Marousi, Greece \\ g Sismanogleio General Hospital, Administration, Marousi, Greece
}

\begin{abstract}
During the COVID-19 pandemic, the number of visits in emergency departments (ED) worldwide decreased significantly based on several studies. This study aims to compare the patient flow in the emergency surgery department during the COVID - 19 pandemic and a control period in the emergency department of a public tertiary care hospital in Greece. The overall patient flow reduction regarding the ED visits between the two examined periods was $49.07 \%$. The emergency surgery department's corresponding visits were 235 and 552, respectively, which indicated an overall patient flow decrease of $57.43 \%$. Chi-square analysis showed that age groups and ambulance use had statistically significant associations with the periods examined. An independent samples t-test was applied and deduced that the average patient's age was statistically significantly higher in the COVID-19 pandemic than in the non-pandemic period. By analyzing hospital information system data, useful conclusions can be drawn to prepare a surgical emergency unit better and optimize resource allocation in a healthcare facility in similar critical situations.
\end{abstract}

Keywords. COVID - 19; coronavirus; emergency departments; emergency surgery department; patient flow; HIS data

\section{Introduction and Background}

The World Health Organization declared on 11 March 2020 a pandemic by Coronavirus disease (COVID-19) [1]. The pandemic of COVID-19 in Greece is part of the global pandemic caused by Severe acute respiratory syndrome coronavirus 2 (SARS-CoV-2).

\footnotetext{
${ }^{1}$ Corresponding Author, Georgios Feretzakis, PhD; E-mail: georgios.feretzakis@ac.eap.gr
} 
The first COVID-19 patient in Greece was diagnosed on 26 February 2020. Cautionary guidelines and recommendations were provided by health and state officials. At the same time, measures were taken locally up to early March 2020, including school closing and suspending cultural activities in the areas affected. The government announced on 10 March that educational institutions of all grades should be suspended. On 13 March, all cafes, bars, shopping centers, sports facilities, and restaurants in the country were closed. On 16 March, all shops were also closed, and any religion or dogma services were suspended in all religious worship fields. From 23 March to 4 May, the Greek authorities declared restrictions on all non-essential movements throughout the country (42-day lockdown).

The first wave of the pandemic involved the adjustment of health systems and hospitals to these new conditions. Intensive care capability had to be expanded, converting rehab facilities and even waiting rooms into ICU beds. Health and nursing workers had been redistributed, and many ambulatory appointments had been postponed. These changes impacted the EDs' functions, including the emergency surgery department (ESD). The ED visits reduction was clearly observed in Spain's, Italy's, and U.S.'s hospitals [2-6]. The patient flow at the ED of a major trauma center in Milan during the first month of the pandemic (12 March to 12 April 2020) compared to the same period in 2019 showed a reduction of 73.8\% [3]. The Centers for Disease Control and Prevention (CDC) compared the number of ED visits from 29 March to 25 April 2020 (early pandemic) with those from 27 to 31 April 2019 to measure the impact of COVID19 on U.S. Emergency department visits. The total number of ED visits during the early pandemic was $42 \%$ lower than the previous year in the same period [4]. Another study [6] in the U.S. showed a decrease in ED visits ranging from $41.5 \%$ in Colorado to $63.5 \%$ in New York.

\section{Methods and Materials}

This research is a retrospective observational study conducted in the ED of a public tertiary care hospital in Greece that has been approved by the Institutional Review Board of Sismanogleio General Hospital (15177/28.07.2020). The raw data is retrieved from the hospital information system (HIS), and statistical analysis was performed with IBM SPSS Statistics version 27.0 [7].

A total of 3,028 ED visits were recorded during the study period (14 March - 4 May 2020) and 5,945 ED visits during the control period (14 March - 4 May 2019). The corresponding visits in the emergency surgery department for the periods mentioned above were 235 and 552, respectively. The study included data regarding ESD visits of 787 patients (mean age: 51.23, median age: 49, standard deviation of age: $21.20,467$ males, 320 females)

Three variables were examined; Age (continuous), Gender (male, female), and whether the patients were transported by ambulance (yes, no). According to Age, the patients were classified into three groups: patients aged $\leq 34$ years, 35-54 years, and $\geq$ 55 years.

Pearson Chi-square tests were used to assess statistical significance association in ESD visits between the three Age groups, the Gender, and the use of ambulance during the two examined periods $(2019,2020)$. Phi and Cramer's V tests were used to measure the strength of association. An independent samples t-test was used to determine whether there is a difference in the patients' mean age between the two groups $(2019,2020)$. 
A significance level of 0.05 was used, and $\mathrm{p}<0.05$ was considered statistically significant.

\section{Results}

The overall patient flow reduction regarding the ED visits between the two periods under examination was $49.07 \%$. The emergency surgery department's corresponding visits were 235 and 552, respectively, which indicated an overall patient flow decrease of $57.43 \%$. The descriptive statistics of the data are presented in the following tables (Tables $1,2)$.

Table 1. Descriptive statistics summary for variables Age, Gender, and use of Ambulance

\begin{tabular}{|l|l|l||c|c|c||c|c|c|}
\hline Age & 2019 & 2020 & Gender & 2019 & 2020 & Ambulance & 2019 & 2020 \\
\hline Mean & 49.99 & 54.12 & Male & 323 & 144 & Yes & 27 & 41 \\
\hline Median & 48.00 & 54.50 & Female & 229 & 91 & No & 525 & 194 \\
\hline St.deviation & 21.39 & 20.55 & Total & 552 & 235 & Total & 552 & 235 \\
\hline
\end{tabular}

Table 2. Descriptive statistics summary for the variable Age groups

\begin{tabular}{|c|c|c||c|c||c|c||c|c|}
\hline $\begin{array}{c}\text { Age } \\
\text { groups }\end{array}$ & \multicolumn{2}{|c||}{$\leq 34$} & \multicolumn{2}{c||}{$35-54$} & \multicolumn{3}{c|}{ Missing values } \\
\hline & Frequency & Pct. & Frequency & Pct. & Frequency & Pct. & Frequency & Pct. \\
\hline 2019 & 147 & $26.6 \%$ & 169 & $30.6 \%$ & 218 & $39.5 \%$ & 18 & $3.3 \%$ \\
\hline 2020 & 45 & $19.2 \%$ & 70 & $29.8 \%$ & 115 & $48.9 \%$ & 5 & $2.1 \%$ \\
\hline Total & 192 & & 239 & & 333 & & 23 & \\
\hline
\end{tabular}

Chi-square analysis showed that age groups $\left(\mathrm{X}^{2}=7.237, \mathrm{p}=0.027<0.05\right)$ and the use of ambulance $\left(\mathrm{X}^{2}=32.916, \mathrm{p}=0.000<0.05\right)$ had statistically significant associations with the time periods examined $(2019,2020)$. Phi and Cramer's V values for the first test both were 0.097, which indicates a weak association. For the second test, the corresponding values were both 0.205 , which indicates the association between ambulance use and the time period was moderate. On the other side, our statistical analysis showed no statistically significant association between Gender and the two time periods $\left(\mathrm{X}^{2}=0.521, \mathrm{p}=0.470>0.05\right)$.

An independent samples t-test was performed, and deduced that the mean patients' age was statistically significantly higher in $2020(54.12)$ than in $2019(49.99)(\mathrm{t}=-2.477$, $\mathrm{p}=0.013<0.05)$, with a mean difference of $4.13(95 \% \mathrm{CI},-7.40,-0.86)$.

\section{Discussion}

The public's behavior and attitudes towards the utilization of emergency services during this pandemic depend on multiple factors that might be different across countries and cultures. Understanding the characteristics of patients attending the ED is of great importance. We analyzed the impact of COVID-19 on the pattern of ED flow and patient parameters in a large tertiary general hospital in Greece. Our results can be compared to 
data from other healthcare settings and inform future research in emergency medicine about the early phase of the pandemic.

In this study, we observed a significant decrease of $57.43 \%$ in the number of ESD visits during the COVID-19 pandemic compared to the non-pandemic period. We also detected a statistically significant association between the age groups of patients who visited ED during the two periods under examination. Furthermore, we showed a statistically significant association between the number of patients transported by ambulance during the pandemic and the non-pandemic period. Furthermore, in our study, an increase in patients' mean age who visited the emergency surgery department was validated as statistically significant by an independent samples t-test.

Several factors could explain the reduction in acute care surgery department visits. First of all, patients could be delayed in attending the EDs to avoid being infected with the SARS-CoV-2 [8,9]. This is probably partially attributed to a general perception that an emergency department is a place of infection [10,11].

Obligatory enforcement restrictions of social contacts, meetings, open-air activities, and sports were considered the safest measure until the arrival of efficient novel antiviral medical therapies and vaccination. These restrictions led to a decline in patients who had experienced road accidents and sports-related injuries [3]. On the other hand, it is known that the number of Emergency Medical Services (EMS) arrivals in EDs, due to the pandemic phase evolution, were increased when compared in the initial baseline phase [12].

A similar study in three Spanish hospitals showed a $65.4 \%$ decline in the number of patients who experienced emergency operations every day in each hospital during the control time period, from 2.6 to 0.9 , during the pandemic period [2,5].

During the outbreak of COVID-19, there was a $25 \%$ decrease in the number of surgical patient visits to the Turkish hospital emergency department. Patients with a green triage code and female patients saw the most significant decline [13]. Another multicenter study involving 18 emergency surgery units in Lombardy's hospitals showed a substantial drop of $45 \%$ in emergency surgery admissions and surgery operations [14].

As stated by our analysis results and similar studies, it seems that there is a drastic decrease in surgery emergency visits worldwide during the COVID-19 outbreak.

\section{Conclusion}

The overwhelming number of COVID-19 patients required a complete reorganization of the healthcare system [3,4]. Wards were converted into COVID-19 care units, and deferrable surgeries and outpatient consultations were suspended. Some hospitals were designated hubs for specific urgent conditions [5], with the need to maximize resources and lessen patient crowding, thus reducing potential nosocomial COVID-19 spread.

The next major step will be implementing new organizational practices as studying important input, throughput, and output factors for ED crowding using existing data from the hospital data warehouse [12]. This will permit a risk stratification guide for severity assessment and triage of suspected or confirmed COVID-19 patients in the ED.

As the COVID-19 pandemic crisis is evolving, this requires careful planning with proper processing and utilization of hospital information system data. Useful conclusions can be drawn that could lead to better preparation of surgery emergency unit and 
optimize the allocation of resources of a health care facility in case of similar critical situations.

\section{References}

[1] WHO Coronavirus disease 2019 (COVID-19) Situation Report - 51 [cited 2021Mar4]. [Internet].Available from: https://apps.who.int/iris/bitstream/handle/10665/331475/nCoVsitrep11Mar2020-eng.pdf.

[2] Cano-Valderrama O, Morales X, Ferrigni CJ, Martín-Antona E, Turrado V, García A, et al. Reduction in emergency surgery activity during COVID-19 pandemic in three Spanish hospitals. Br JSurg. 2020 May;107. https://doi.org/10.1002/bjs.11667

[3] Luceri F, Morelli I, Accetta R, Mangiavini L, Maffulli N, Peretti GM. Italy and COVID-19: the changing patient flow in an orthopedic trauma center emergency department. J Orthop Surg Res. 2020 Aug 14; 15(1):323. https://doi.org/10.1186/s13018-020-01816-1

[4] Hartnett KP, Kite-Powell A, DeVies J, et al. Impact of the COVID-19 Pandemic on Emergency Department Visits - United States, January1, 2019May 302020. MMWR Morb MortalWkly Rep. 2020 Jun;69(23):699-704. https://dx.doi.org/10.15585/mmwr.mm6923e1

[5] Cano-Valderrama O, Morales X, Ferrigni CJ, Martín-Antona E, Turrado V, García A, et al. Acute Care Surgery during the COVID-19 pandemic in Spain: Changes in volume, causes and complications. A multicentre retrospective cohort study, Int J Surg, 2020 Aug; 80:157-161, https://doi.org/10.1016/j.ijsu.2020.07.002.

[6] Jeffery MM, D'Onofrio G, Paek H, Platts-Mills TF, Soares WE, Hoppe JA, et al. Trends in Emergency Department Visits and Hospital Admissions in Health Care Systems in 5 States in the First Months of the COVID-19 Pandemic in the US. JAMA Intern Med. 2020 Oct;180(10):1328-1333. https://doi.org/10.1001/jamainternmed.2020.3288

[7] IBM Corp. Released 2020. IBM SPSS Statistics for Windows, Version 27.0. Armonk, NY: IBM Corp

[8] Patriti A, Eugeni E, Guerra F. What happened to surgical emergencies in the era of COVID-19 outbreak? Considerations of surgeons working in an Italian COVID-19 red zone. Updates Surg. 2020 Jun;72(2):309-310. https://doi.org/10.1007/s13304-020-00779-6

[9] Slim K, Veziant J. Urgent digestive surgery, a collateral victim of the COVID-19 crisis? J Visc Surg. 2020 Jun;157(3S1):S5-S6. https://doi.org/10.1016/j.jviscsurg.2020.04.001

[10] Man CY, Yeung RS, Chung JY, Cameron PA. Impact of SARS on an emergency department in Hong Kong. Emerg Med (Fremantle) . 2003;15:418-22. https://doi.org/10.1046/j.1442-2026.2003.00495.x

[11] Heiber M, Lou WW. Effect of the SARS outbreak on visits to a community hospital emergency department. Cjem. 2006;8:323-8. https://doi.org/10.1017/S148180350001397X

[12] Ugglas BA, Skyttberg N, Wladis A, Djärv T, Holzmann MJ. Emergency department crowding and hospital transformation during COVID-19, a retrospective, descriptive study of a university hospital in Stockholm, Sweden. Scand J Trauma, Resusc Emerg Med. 2020 Oct;28(1):107. https://doi.org/10.1186/s13049-020-00799-6

[13] Goksoy B, Akca MT, Inanc OF. The Impact of the COVID-19 Outbreak on Emergency Department Visits of Surgical Patients. Ulus Travma Acil Cerrahi Derg. 2020; 26(5): 685-692.. https://doi.org/10.14744/etd.2020.67927.

[14] Rausei S, Ferrara F, Zurleni T, Frattini F, Chiara O, Pietrabissa A, et al. Dramatic decrease of surgical emergencies during COVID-19 outbreak. JTrauma Acute Care Surg. 2020 Dec; 89(6):10851091.https://doi.org/10.1097/TA.0000000000002923. 